\title{
Relation between height velocity and fasting insulin concentrations
}

\author{
P C HINDMARSH, D R MATTHEWS, * L DI SILVIO, A B KURTZ, AND C G D BROOK \\ Endocrine Unit, Middlesex Hospital London and"Diabetes Research Laboratories, Radcliffe Infirmary, \\ Oxford
}

SUMMARY A linear relation between fasting serum insulin concentration and height velocity was found in 47 normal children. This suggests that doubling of growth velocity at puberty is accompanied by a two to threefold rise in insulin. This implies that insulin dosage should be increased by a similar magnitude in pubertal diabetic children during their growth spurt.

It is widely accepted that good diabetic control leads to a reduction in the longterm complications of diabetes. ${ }^{1}$ In children with diabetes this control has to be established upon the background of the changing endocrine milieu of growth and pubertal development. We have recently shown important changes in parameters of insulin secretion in association with puberty and concluded that changes in circulating growth hormone concentrations could produce these effects. In diabetics, changes in insulin dosage need to parallel these events and we now describe a simple relation between fasting insulin concentration and growth velocity that might be of value to clinicians looking after such patients.

\section{Subjects and methods}

Forty seven children ( 25 boys and 22 girls) aged between $4 \cdot 2$ and $16 \cdot 4$ years who attended the growth disorder clinic at the Middlesex Hospital were studied. These children were being investigated for disorders of growth and comprised tall and short, prepubertal, and pubertal children. The short prepubertal children were part of a cohort reported previously, ${ }^{2}$ and the samples from these children were obtained during their (delayed) pubertal growth spurt. Standard auxological assessment was performed over one year. ${ }^{3}$ The blood samples were obtained at the mid point of the yearly assessment to accord with standard reporting of height velocity. Blood samples for the measurement of serum insulin concentration were taken at 0800 hours after an overnight fast. Plasma was separated immediately and stored at $-20^{\circ} \mathrm{C}$ until measured using a double antibody radioimmunoassay. ${ }^{+}$
The intra-assay and interassay coefficients of variation for the insulin radioimmunoassay were $3.6 \%$ and $9.6 \%$ respectively at serum insulin concentrations between 20 and $25 \mathrm{mU} / \mathrm{l}$. The sensitivity of the assay was $2.0 \mathrm{mU} / \mathrm{l}$.

The relation between fasting serum insulin concentration and height velocity was investigated by linear regression and the calculation of Pearson's correlation coefficient. The possible contribution of age and stage of puberty were studied by stepwise multiple regression analysis.

\section{Results}

Of the 47 children, 24 were prepubertal (seven tall, 17 short) and 23 pubertal (15 tall, eight short). The relation between fasting serum insulin concentration (y) and height velocity $(\mathrm{x})$ is shown in the figure and described by the linear regression equation: $y=2 \cdot 1 x$ $-5.8(\mathrm{r}=0.74 ; \mathrm{p}<0 \cdot 001)$.

Introducing pubertal staging into the regression

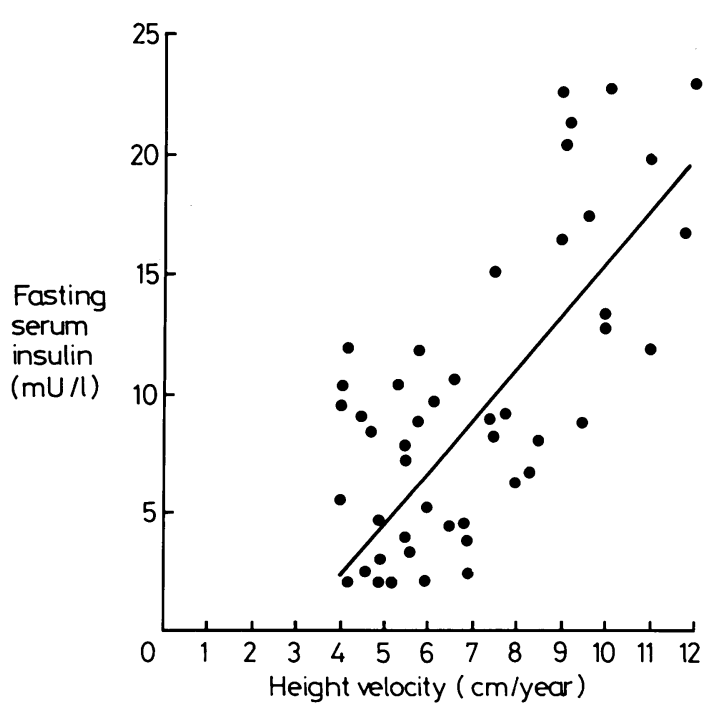

Figure The relation between fasting insulin concentration and height velocity. 
equation increased $\mathrm{r}$ to $(0 \cdot 79$. Age added little more $(\mathrm{r}=0 \cdot 80)$.

\section{Discussion}

These data show a simple linear relation between height velocity and fasting serum insulin concentration. This association is probably indirect and secondary to changes in circulating growth hormone concentration. Growth in mid childhood is growth hormone dependent while that of puberty results from synergism between growth hormone and circulating sex steroids. ${ }^{25}$ High circulating concentrations of growth hormone are known to increase fasting insulin concentrations and to promote insulin resistance at peripheral tissues. ${ }^{\prime}$

The model proposed supports the observation of an increase in serum insulin concentrations associated with puberty. It suggests that a two to threefold rise in fasting serum insulin concentration occurs as a result of a change in growth velocity from pubertal values of about $5.5 \mathrm{~cm} /$ year to that seen during the pubertal growth spurt of $10 \mathrm{~cm} /$ year or more. These data may have importance for clinicians caring for pubertal diabetic patients. If the findings of this study were extrapolated as an index to total daily insulin requirement, such patients might need up to a threefold increase of insulin dosage to maintain euglycaemia and an acceptable growth spurt. As growth hormone secretion decreases after puberty it is possible that insulin requirements will also fall in adulthood.

\footnotetext{
References

I Pirart J. Diabetes mellitus and its degenerative complications: a propective study of $44(0)$ patients observed between 1947 and 1973. Diabetes Care 1978:1:168-88.252-63.

2 Hindmarsh P. Smith PJ. Brook CGD, Matthews DR. The relationship between height velocity and growth hormone secretion in short prepubertal children. Clin Endocrinol (Oxf) 1987:27:581-91.

Brook CGD. Growth assessment in childhood and adolescence. Oxford: Blackwell Scientific Publications, 1982

4 Morgan CR. Lazarow A. Immunoassay of insulin: two antibody system. Diabetes 1963:12:115-26.

Mauras N. Blizzard RM. Link K. Johnson ML. Rogol AD. Veldhuis JD. Augmentation of growth hormone secretion during puberty: evidence for a pulse amplitude-modulated phenomenon. J Clin Endocrinol Metab 1987:64:596-601.

6 Rosenfeld RG. Wilson DM. Dollar LA, Bennett A, Hintz RE. Both human pituitary growth hormone and recombinant DNA derived human growth hormone cause insulin resistance at a postreceptor sitc. J Clin Endocrinol Metab 1982:54:1033-8.
}

Correspondence to Dr CGD Brook. Endocrine Unit, Middlesex Hospital, Mortimer Street. London WIN 8AA

Accepted 20 January 1988

\title{
Prepubertal hypertrichosis: normal or abnormal?
}

\author{
J H BARTH, J D WILKINSON, * AND R P R DAWBER \\ Departments of Dermatology, Slade Hospital, Oxford, and "Wycombe General Hospital, High Wycombe
}

SUMMARY The pattern of hair growth, morphology of the hair shafts, and the hair root state are described in four girls and two boys with prepubertal hypertrichosis. The exact nosology of this form of excessive hair growth is discussed in relation to hirsuties and the possibility of it representing an 'atavistic' trait.

Hypertrichosis in childhood may be seen in a variety of congenital and metabolic disturbances, after administration of therapeutic agents in utero, and after birth and in association with chronic disease. ${ }^{1}$ In most of these disorders the excess hair growth is not considered to be a major component and is usually noted only for completion. In contrast, most cases of hypertrichosis lanuginosa have been re- ported because the excess hair growth is the primary disorder.

We report a series of children with hypertrichosis as this pattern appears to have been ignored or, conversely, given the diagnostic label of hirsuties: the latter is a diagnosis that suggests an aetiology of androgen hormone excess.

\section{Case reports}

Six children with noticeable congenital generalised hypertrichosis were seen. There were two boys (ages $31 / 2$ and $71 / 4$ ) and four girls (ages $23 / 4,6,61 / 2$, and 8 ). Two boys and one girl were Asian; one of the other three girls had a Celtic father, the other parents were Anglo Saxon. Five of the children had dark hair and only one had blonde hair. Five of the children had no family history of excess hair. One of 